\title{
Viral Viruses and Modified Mobility: Cyberspace Disease Salience Predicts Human Movement Patterns
}

\author{
Michał Folwarczny ${ }^{1}$, Nils Magne Larsen ${ }^{2}$, Tobias Otterbring ${ }^{3,4}$, Agata \\ Gasiorowska $^{5}$, and Valdimar Sigurdsson ${ }^{1}$ \\ ${ }^{1}$ Department of Business Administration, Reykjavik University \\ ${ }^{2}$ The Business School, UiT The Arctic University of Norway \\ ${ }^{3}$ Department of Management, University of Agder \\ ${ }^{4}$ Institute of Retail Economics \\ ${ }^{5}$ Faculty of Psychology in Wroctaw, SWPS University of Social Sciences and Humanities
}

\footnotetext{
${ }^{1}$ Corresponding author: Michał Folwarczny (michalf@tuta.io). Author contributions: Conceptualization: MF, TO, VS, AG; Data curation: MF, NML; Data analysis \& visualization: MF; Writing-Original draft: MF, NML, VS; Writing-Review \& Editing: TO, VS, NML, AG; Funding acquisition: VS. Data deposition: Data necessary to reproduce findings from Studies 1 and 3 are publicly available. Sales data used in Study 2 are confidential. Funding: This research was supported by the Icelandic Research Fund (Project Grant awarded to Valdimar Sigurdsson number 218235-051). The funding sources have no involvement in the research.
} 


\begin{abstract}
Humans have a motivational system that influences cognition and behavior to minimize the risk of contact with pathogens whenever cues to disease emerge. The current research examines the relationship between cyberspace disease salience and mobility behavior at the macro and micro levels. Across three studies, we predict and find that people adjust their mobility behavior to minimize the risk of close physical contact with strangers when cyberspace disease salience is high (vs. low). Study 1 examines web searches for terms related to the pandemic to determine relatively high and low disease salience periods in cyberspace. In Study 2, we analyze hourly sales data from five grocery stores and find that when cyberspace disease salience is high (vs. low), consumers spend $28 \%$ more money on each shopping trip and that grocery stores sell $10 \%$ more items per hour despite $10 \%$ fewer shoppers per hour. Finally, in Study 3, we test the generalizability of these results by analyzing the Google Community Mobility Reports. Here we find that high (vs. low) cyberspace disease salience is associated with an overall decrease in mobility in contexts where the risk of close contact with strangers is high - but not low, whereby we observe an increase in mobility.
\end{abstract}

Keywords: cyberspace, pathogens, disease, behavioral immune system, mobility, consumer behavior 


\section{Introduction}

Humans have been exposed to pathogens throughout evolutionary history, including infectious diseases that have occasionally decimated populations and necessitated migration from one place to another. As a result, natural selection has equipped them with defense mechanisms that respond to disease salience and, in turn, guide cognition and behavior (Murray \& Schaller, 2016; Schaller \& Park, 2011; Tybur \& Lieberman, 2016). In cyberspace, content related to the current COVID-19 pandemic exemplifies disease salience, with netizens' interest in such content being predictive of large-scale human dispersion or mobility (Ma, 2022). Yet, little is known about the relationship between cyberspace disease salience and people's mobility in particular locations. For example, do people get up an hour earlier to go grocery shopping when stores are nearly empty at times when they are widely exposed to information about disease threats?

In the current research, we develop a framework to examine how cyberspace disease salience is related to macro- and micro-level mobility patterns. Most existing studies on related topics focus primarily on the relationship between mobility patterns, typically measured using cell phone data, and SARS-CoV-2 transmission and adherence to preventive measures to slow the spread of the virus (Levin et al., 2021; Nouvellet et al., 2021; Van Bavel et al., 2022). These data, often aggregated at the country level, are insufficient to examine people's mobility behavior at the micro-level. Other studies exploring how disease salience affects micro-level mobility show that disease salience is positively related to increased interpersonal and psychological distance preferences, understood as contact comfort, especially with strangers (e.g., Tybur et al., 2020; Welsch et al., 2021). However, these studies generally rely on self-reported tendencies without analyzing actual microlevel mobility behavior in particular locations, thus limiting the ecological validity of their findings (for a detailed discussion of this issue, see Doliński, 2018; Nisbett \& Wilson, 1977; Otterbring et al., 2020).

Building on the behavioral immune system framework (Murray \& Schaller, 2016; Schaller \& Park, 2011; Tybur \& Lieberman, 2016), we propose that people extensively exposed to the disease-related content in cyberspace adjust their mobility behavior to minimize the risk of close physical encounters with strangers. They should do this by limiting visits to places where proximity to strangers is relatively difficult to avoid but not to places where proximity to strangers is easy to avoid. For instance, grocery stores generally pose a high risk of close contact with others because they are designed so that most customer traffic occurs in a relatively small portion of the store's total space (Hui et al., 2009; Larsen et al., 2020; Larson et al., 2005; Sorensen et al., 2017). The greater the number of customers entering a store in a given time, the greater the risk.

Our work has three overarching goals: (a) to identify periods when disease salience is highest in cyberspace; (b) to examine micro-level mobility behavior in grocery stores when cyberspace disease salience is high compared to low; and (c) to examine macro-level mobility behavior in different locations when cyberspace disease salience is high compared to low.

We address these objectives in three studies. In Study 1, we use Google Trends to identify the periods with the highest and lowest disease salience in cyberspace in the first half of 2020 , i.e., the periods with the highest and lowest presence and interest in content related to the coronavirus. In Study 2, we analyze hourly data from five grocery stores in Norway 
over these periods, including the value of the average shopping cart, the average number of items sold per hour, and the average number of shoppers per hour. In Study 3, we use the Google Community Mobility Reports (movement trends), which are based on cell phone location history, and analyze mobility in six types of locations in selected European countries during these periods.

We restrict our analysis to European countries for several reasons. We seek to make meaningful comparisons of mobility behavior at the macro and micro levels simultaneously during relatively high and low cyberspace disease salience. To this end, our micro-level mobility data (Study 2) should be temporally and spatially aligned with the macro-level mobility data (Study 3). The micro-level data came from grocery stores in Norway, and this country coordinated its response to the COVID-19 pandemic with many other European countries. In fact, the timing of specific pandemic containment measures - an indicator of cyberspace disease salience - was relatively uniform across Europe in the early stages of the COVID-19 outbreak, as the European Council and the World Health Organization (WHO) largely influenced national policies across the continent.

Our results show a consistent micro-level mobility pattern across five grocery stores: customers spend an average of $28 \%$ more money during a single shopping trip when cyberspace disease salience is high (vs. low), and stores sell $10 \%$ more items per hour even though the number of customers is $10 \%$ lower under these circumstances. This tendency among people to avoid close physical encounters with others during high (vs. low) can be generalized to macro-level mobility patterns across Europe, with mobility vastly decreasing under conditions of high (vs. low) cyberspace disease salience in all but residential areas, characterized by increasing mobility at that time. This finding suggests that when cyberspace disease salience is high (vs. low), people tend to avoid places where the risk of close contact with strangers is high (vs. low), but they compensate for this decrease in mobility by increasing their presence in places where the risk of such contact is low (vs. high).

Compared to existing studies, which often focus only on macro-level mobility behavior during the pandemic or on self-reported preferences for spatial proximity to others, we find similar mobility patterns at both levels of analysis. To our knowledge, this study is the first to examine hourly shopping data from brick-and-mortar grocery stores during the pandemic. Our study, inspired by research on the behavioral immune system (Murray \& Schaller, 2016; Schaller \& Park, 2011; Tybur \& Lieberman, 2016), may partially explain why Americans increasingly preferred to live in larger homes farther from urban centers after the pandemic outbreak (Gómez, 2021). These results also contribute to research on food waste and sustainable travel behaviors and raise questions about how cyberspace content may affect the economic viability of retail stores during the spread of infectious diseases. 


\section{Literature review and the current research}

Mobility is an essential aspect of human behavior. Every day, billions of people around the world commute to their jobs, parks, and shopping malls. When commuting between locations, people choose the mode of transportation and the time when they travel. For example, those with flexible work schedules can choose to travel to the office before or during rush hour. Similarly, people can choose to visit grocery stores during rush hour and thus join the crowds or postpone their shopping to another day or time of day to avoid the crowds.

The current COVID-19 pandemic has prompted governments around the world to impose lockdowns to contain the spread of the virus, leading to a macro-level decrease in overall mobility (Nouvellet et al., 2021). This decrease in mobility was particularly pronounced in areas historically affected by infectious diseases and was positively associated with online searches for pandemic-related content - an indicator of people's concerns about the disease (Ma, 2022). However, the decline in mobility was unequal depending on the type of mobility behavior. For example, Abu-Rayash and Dincer (2020) examined the change in mobility between the pre-pandemic period (December 2019) and during the first months of the pandemic (January 2020 to April 2020). They found that civilian and military mobility decreased by 20 to 76 percent after the pandemic outbreak. However, private and other mobility declined by only 6 percent, suggesting that people selectively adjusted their mobility patterns during the pandemic. Apart from the obvious reasons for this decline, such as the need to work from home and partial lockdowns, fear of COVID-19 was also positively related to a macro-level decline in mobility, at least that captured by self-reported measures (Borkowski et al., 2021).

Another line of research focuses on the impact of disease salience on micro-level aspects of mobility behavior, emphasizing changes in preferred interpersonal distances. Although these preferences are culturally determined and depend on demographic variables such as sex and age (Sorokowska et al., 2021; Sorokowska et al., 2017), when people interact with strangers, they typically maintain between 75 to 125 centimeters of distance while preferring lower physical distance to acquaintances and even closer distances in intimate relationships. However, disease salience can also influence interpersonal distance preferences (Otterbring, 2021; Roggeveen \& Sethuraman, 2020). Indeed, after the pandemic outbreak, people's preferred interpersonal distances swung with the number of infections but remained higher than pre-pandemic levels during periods of low infection rates (Welsch et al., 2021). This tendency to avoid close physical contact with people also applies to objects. For example, after the pandemic outbreak, people were less likely to touch fresh fruits and vegetables when shopping and showed a lower preference for cash payments, while preference for contactless payment methods increased (Otterbring \& Bhatnagar, 2022). All in all, as a result of the ongoing pandemic, consumers are likely to prefer a greater distance from service staff and other customers and expect people to respect their personal space (Otterbring, 2022).

We propose that shifts in mobility patterns at both the micro and macro levels can be explained in part through the lens of the behavioral immune system (Murray \& Schaller, 2016; Schaller \& Park, 2011; Tybur \& Lieberman, 2016). According to this framework, humans have a motivational immune system that influences their cognition and behavior to minimize the risk of contact with pathogens once environmental cues to those pathogens are present and recognized (Ackerman et al., 2018). Such avoidance of contact with 
pathogens, which can be achieved, for example, by avoiding physical proximity to others who appear to be infected, provides adaptive benefits because contact with pathogens is risky and requires activation of the somatic immune system that is energetically costly (Van Leeuwen \& Petersen, 2018). In the context of the current pandemic, research has shown that activation of the behavioral immune system is positively related to a preference for greater interpersonal distance and negative emotions toward strangers, as well as lower frequency of interpersonal contact (Hromatko et al., 2021). Crucially, however, people's comfort with infection-risky contact with others depends on the value they place on a target. In the context of our research, it is important to note that people feel most comfortable with infection-risky contacts with romantic partners, followed by friends, acquaintances, and strangers, respectively (Tybur et al., 2020).

Based on this framework, we draw two primary predictions. First, in times of high (vs. low) cyberspace disease salience, people should adjust their shopping behavior to minimize the risk of close contact with strangers so that they make more purchases during a single shopping trip and therefore visit grocery stores less frequently. Second, during periods of high (vs. low) cyberspace disease salience, people's mobility should vary in different areas depending on the risk of coming into close physical contact with strangers in those areas. For example, at bus stations or shopping malls, a person mainly encounters strangers. In residential areas, on the other hand, the same person interacts mainly with family, friends, and acquaintances. Therefore, we should observe a decrease in mobility in the former but not in the latter areas.

\section{$1 \quad$ Study 1}

We conducted Study 1 to identify the periods of highest and lowest disease salience in cyberspace in the first half of 2020 . We chose this time period because the data used in Study 2-obtained from Norwegian retailers-ranged from January 2 to June 20, 2020. We further tested whether critical announcements of pandemic containment measures corresponded with disease salience in cyberspace.

\subsection{Method}

\subsection{Data}

We took several steps to ensure that the division of the periods into high and low cyberspace disease salience was justified. First, we sought to maintain consistent periods across studies. Because we use sales data from Norway in Study 2, we rely on dates of specific COVID-19-related announcements by the Norwegian government; however, the periods of many pandemic containment measures were similar in most European countries in 2020. The first case of COVID-19 infection in Norway was reported on February 26, and the first patient was hospitalized on March 6, 2020. The government announced a partial lockdown on March 12, which went into effect on March 16. The country's policymakers announced a gradual easing of restrictions on May 7, 2020 (The Norwegian Government, 2022).

We analyzed Google Trends data that show the relative frequencies of web searches for specific keywords. Here we compared the total number of web searches for the terms "covid" and "coronavirus" (other pandemic-related words were relatively rarely searched on Google) in the world and specifically in Norway. Tthese data are publicly available at 
https://trends.google.com/trends/. As a second piece of evidence behind the adequacy of our division of time periods, we analyzed the numbers of daily SARS-CoV-2 infections and associated deaths in Norway as reported by the World Health Organization (WHO). These data can be accessed at https://covid19.who.int/region/euro/country/no.

\subsection{Results and discussion}

The relative frequencies of web searches for the two terms related to the pandemic were highly correlated in Norway and in the world $(r=.50$ and $r=.68$, respectively); hence, we averaged them to create an index of cyberspace disease salience. We then divided the time periods into three categories: before the (partial) lockdowns in Norway, that is, from January 1 to March 11, during the lockdowns from March 12 to May 6, and after the lockdowns from May 7 to June 20, 2020.

First, we analyzed data from Norway. A one-way ANOVA revealed significant differences in web searches of the COVID-19-related terms between these three time periods, $F(2$, $169)=33.01, p<.001, \eta_{p}^{2}=.28$. A post-hoc analysis with Tukey adjustment revealed that searches for terms related to the pandemic were more frequent between March 12 and May 6 than in the periods before and after (both $p s<.001$ ), which did not differ significantly from one another $(p=.177)$. We repeated these analyzes using the combined worldwide data. Again, we found differences in web searches for terms related to the pandemic between the time periods, $F(2,169)=208.39, p<.001, \eta_{p}^{2}=.71$. A similar post-hoc analysis found that searches for terms related to the pandemic were more frequent between March 12 and May 6 than in the other two time periods (both $p s<.001$ ), which again did not differ significantly from one another $(p=.482)$.

Next, we analyzed WHO data. We found a significant difference in daily new infections across the three time periods in Norway (WHO data cover the period from January 3, $2020), F(2,167)=84.92, p<.001, \eta_{p}^{2}=.50$. A post-hoc analysis with Tukey adjustment revealed that there were more new COVID-19 cases daily between March 12 and May 6 than in the periods before and after (both $p s<.001$ ), but again, these two periods were not significantly different from one another $(p=.834)$. Similarly, we found a difference in daily deaths across the three periods, $F(2,167)=40.57, p<.001, \eta_{p}^{2}=.33$. A post-hoc analysis revealed that there were more new COVID-19-related deaths between March 12 and May 6 than in the periods before and after (both $p s<.001$ ), with the latter two periods not significantly different from one another $(p=.201)$. Figure 1 depicts these findings. 
Figure 1

Public interest in disease-related topics and the effects of the pandemic on public health in 2020
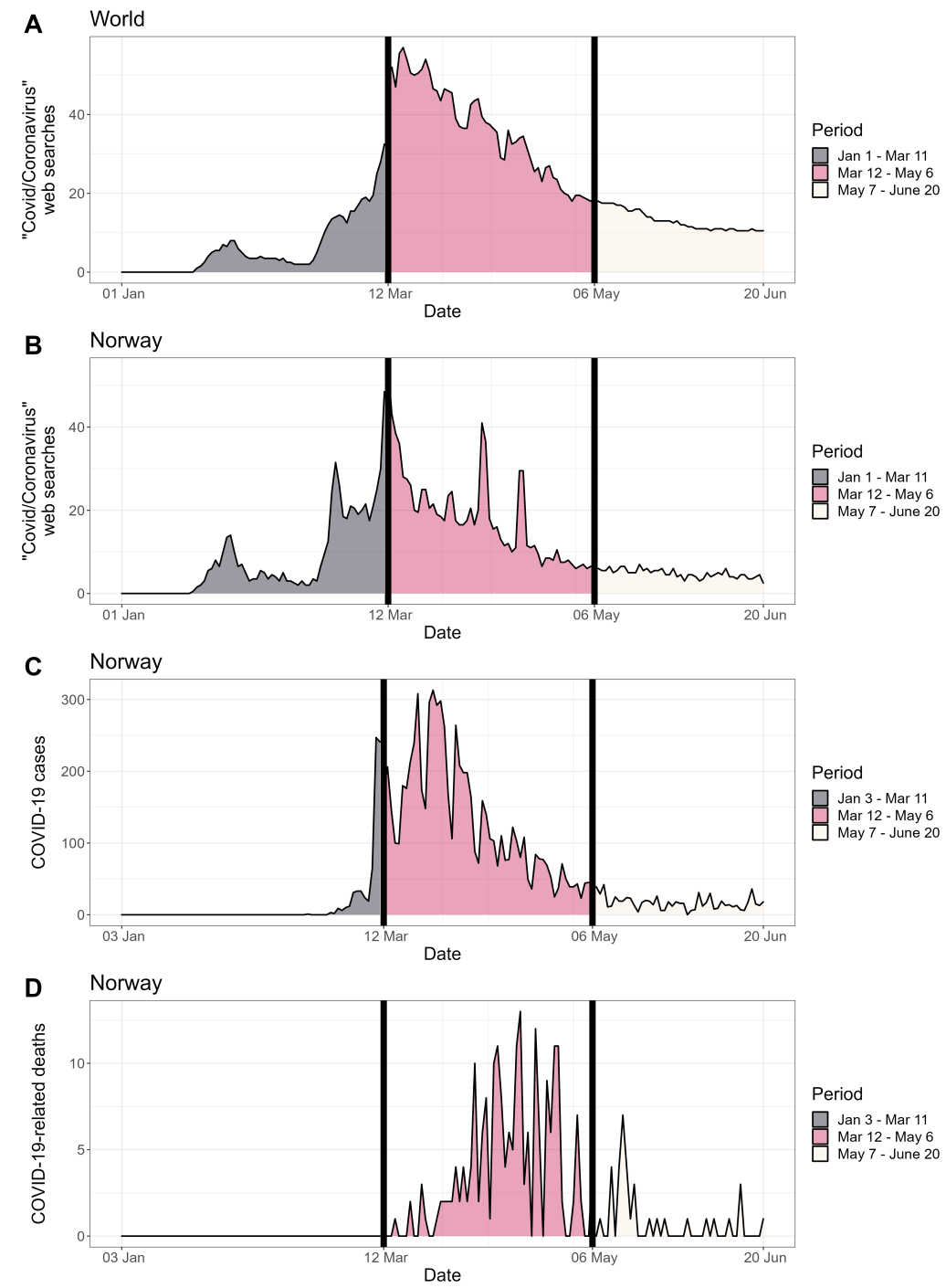

The results of Study 1 show that public interest in the pandemic-related terms in cyberspace was higher during the period referred to as "high cyberspace disease salience" (March 12-May 6, 2020) than during the period referred to as "low cyberspace disease salience" (January 1-March 11 and May 7-June 20, 2020) in the world and in Norway, where there were significantly more COVID-19 infections and deaths during this period than during the periods before and after, which we merge to facilitate parsimonious analysis and refer to as "low cyberspace disease salience" in the remainder of this article.

\section{$2 \quad$ Study 2}

The results of Study 1 provided evidence for our distinction between periods of relatively high and low cyberspace disease salience. However, it remains unclear whether people's micro-level mobility behavior changes during these periods. Therefore, in Study 2, we test the prediction that when cyberspace salience is high (vs. low), people adjust their 
mobility behavior to minimize the risk of close physical encounters with strangers. Studying consumer shopping behavior in grocery stores, where some degree of physical contact with strangers is inevitable due to the nature of their shared environment (many people touch products while selecting them, and aisles between shelves are sometimes narrow), provides a perfect opportunity to test our prediction under ecologically valid conditions. Therefore, in Study 2, we examine whether consumer shopping behavior changes when cyberspace disease salience is high (vs. low), such that the frequency of physical contact with strangers decreases, thus reducing the risk of pathogen exposure.

\subsection{Method}

\subsection{Data}

The data for Study 2 came from five grocery stores in Norway belonging to Coop Norge SA - one of the leading grocery retailers in the country. These stores were located in three municipalities that are in the northern part of Norway. None of these grocery stores were closed during the period studied herein.

The units of analyzes in Study 2 were 11,055 hourly sales data points that represented the following dependent variables: the average size of the shopping basket in Norwegian kroner $(1 \mathrm{NOK}=0.11 \mathrm{USD})$, the average number of items sold per hour, and the average number of shoppers per hour. Additionally, we collected the following variables: store code (1-5), date (from January 2 to June 20, 2020), and time (stores were open between 7:00 and 23:00; sales data at, for example, 22:44 were coded as 22, so this variable ranged from 7 to 22). To remain consistent, we split these data in the same manner as in Study 1, such that the high cyberspace disease salience period ranged from March 12 to May 6, 2020, whereas data before and after this period were coded as low in cyberspace disease salience.

\subsection{Results and discussion}

We fit linear mixed models to our data using the lme4 package for R (Bates et al., 2015), and obtained $p$-values with the lmerTest package (Kuznetsova et al., 2017). As a predictor (fixed effect), we added cyberspace disease salience to the model, coded as "high" (March 12-May 6, 2020) or "low" (February 15-March 11 and May 7-June 20, 2020). Considering that it was expected that shopping activities differed depending on the characteristics (e.g., size) of a grocery store, or date (e.g., a day preceding an important sports event), we allowed (random) intercepts to vary across stores (coded as 1-5) and dates (coded as date ranging from January 2 to June 20, 2020). The exclusion of outliers, defined as data points exceeding $1.5 \times$ interquartile range above the third and below the first quartile (Tukey et al., 1977; Van den Bergh et al., 2008), did not change the nature or significance of our results. Figure 2 shows hourly changes in shopping behavior during periods of high and low cyberspace disease salience, respectively, with data divided into peak hours (eight hours in the middle of the day with the highest sales) and off-peak hours (four first and four last opening hours) for illustrative purposes. Descriptive statistics can be found in Table S1 in the Appendix.

According to the estimates of our model, the average basket size increased by NOK 78.59, or USD 8.75, when cyberspace disease salience was high relative to low $(b=78.59, S E=$ $7.76, t=10.12, p<.001$ ). Similarly, when cyberspace disease salience was high (vs. low), 
there were on average 78 more items sold per hour $(b=77.82, S E=37.78, t=2.06, p=$ .041 ). Finally, when cyberspace disease salience was high (vs. low), there were on average eight fewer buyers in grocery stores per hour $(b=-8.18, S E=2.12, t=-3.85, p<.001)$.

Figure 2

Shopping activities plotted by hour

\section{A Average basket size (NOK)}
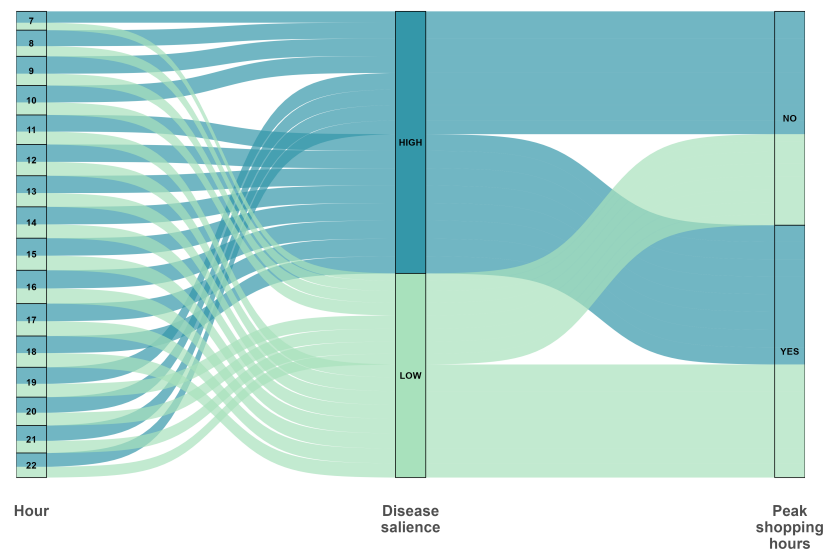

B

Items sold per hour
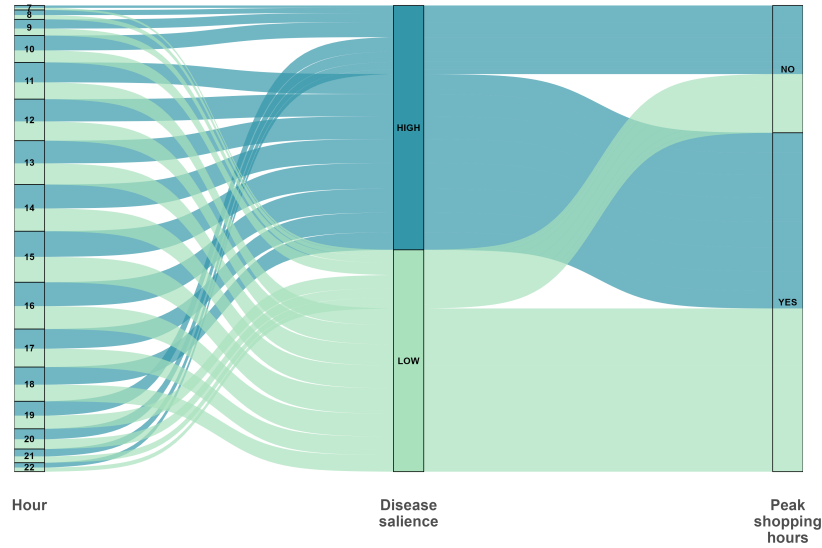

C Shoppers per hour

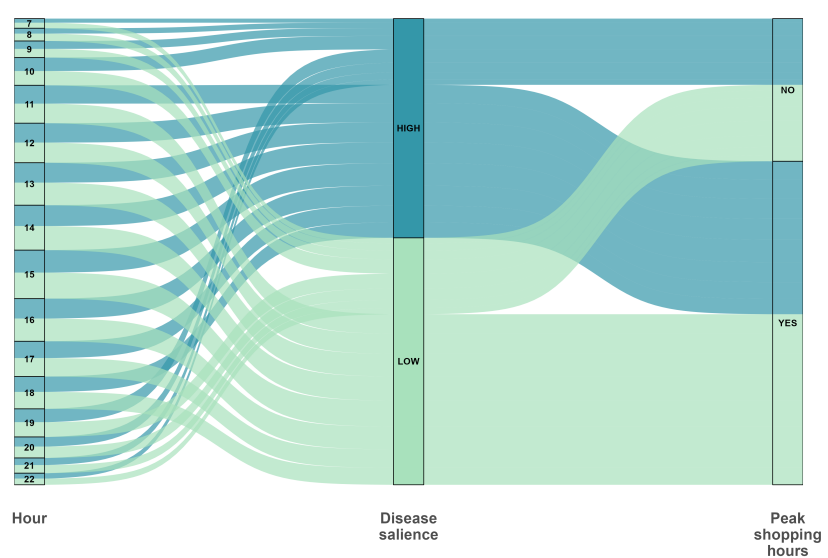

Note. The alluvial plots show hourly shopping activities in five grocery stores in Norway in 2020, separately for the two periods coded as high (March 12-June 6) and low (January 2-March 11 and May 7-June 20) cyberspace disease salience. The eight hours with the highest average number of shoppers per hour were coded as peak (yes $=$ 11:00-18:59), whereas the remaining eight hours were coded as off-peak hours (no = 07:00-10:59 and 19:00-22:59). 
The size of stack bars corresponds to the mean values belonging to each category. The size of the segments corresponds to the the mean values belonging to the category matching these segments. For example, a higher "Disease salience" bar in the "A" panel indicates that the average basket size was higher during a high (vs. low) disease salience. Likewise, a higher bar in the "C" panel marked as "15" compared to the bar marked as "7" means that there were considerably more shoppers in the grocery stores per hour between 15:00-15:59 than between 7:00-7:59.

We performed additional analyzes by including the average number of shoppers per hour (i.e., store crowding, which is a proxy measure for peak vs. off-peak shopping hours) in the interaction term with cyberspace disease salience. Below, we report standardized regression coefficients for readability (see Tables S2 and S3 in the Appendix for full model results). This analysis revealed a significant interaction between cyberspace disease salience and the number of hourly shoppers on the average basket size $(\beta=.11, S E=$ $.01, t=9.75, p<.001)$, such that the slope of the number of hourly shoppers was steeper for high (vs. low) cyberspace disease salience (see Figure 3, left panel).

We decomposed this interaction to understand its nature using the package interactions for R (Long, 2019). Here we examined the conditional effects of cyberspace disease salience on the average basket size at the three levels of the moderator (the average number of shoppers per hour or store crowding), i.e., low ( $M-1 S D=15$ shoppers), medium ( $M$ $=73$ shoppers $)$, and high $(M+1 S D=131$ shoppers $)$. We found that the effects of cyberspace disease salience were significant at low $(\beta=.46, S E=.05,95 \%$ CI $[.35, .56])$, medium $(\beta=.57, S E=.05,95 \%$ CI $[.47, .67])$, and high $(\beta=.68, S E=.05,95 \%$ CI $[.58$, $.79])$ levels of the moderator, i.e, store crowding. Importantly, the confidence intervals around the slopes of cyberspace disease salience between the low and high levels of the moderator did not overlap, suggesting that our focal effect was stronger in highly crowded stores than in stores visited by relatively few customers per hour.

We repeated this analysis for the second dependent measure - the average number of items sold per hour-and again found a significant interaction $(\beta=.24, S E=.01, t=31.62$, $p<.001$ ), indicating a steeper slope of the number of hourly shoppers on the average number of items sold per hour at high (vs. low) cyberspace disease salience. The conditional effects of cyberspace disease salience on the average number of items sold per hour were not significant at low values of the moderator $(\beta=-.03, S E=.03,95 \%$ CI [-.09, $.03])$ but were significant at medium $(\beta=.21, S E=.03,95 \%$ CI $[.15, .26])$ and high values $(\beta=.44, S E=.03,95 \%$ CI $[.39, .50])$. Again, the confidence intervals around the slopes of cyberspace disease salience between the medium and high levels of the moderator did not overlap, suggesting that the effect was stronger in highly crowded stores than in moderately crowded stores. Finally, we investigated how many consumers per hour on average had to be present in stores for the effect of cyberspace disease salience to occur. We calculated Johnson-Neyman intervals and found that the effect of cyberspace disease salience on the average number of items sold per hour occurred only in moderately to heavily crowded stores when there were more than 36 shoppers per hour (-0.6 SD below the mean of the number of hourly shoppers; see Figure 3, right panel).

Our results suggest that, on average, consumers bought more during a single shopping trip when cyberspace disease salience was high (vs. low), as indicated by the larger average basket size and the higher average number of items sold per hour. The opposite was true for the average number of shoppers - there were fewer shoppers per hour when cyberspace disease salience was high (vs. low). In addition, we found a significant interaction effect 
between cyberspace disease salience and the average number of shoppers per hour on the average size and the number of items sold per hour, as evidenced by steeper slopes in the high (vs. low) cyberspace disease salience period (see Figure 3). Specifically, when stores were more (vs. less) crowded, the effect of cyberspace disease salience on the average basket size and the average number of items sold per hour was stronger (vs. weaker). However, in terms of the average number of items sold per hour, the effect of cyberspace disease salience occurred only in moderately to heavily crowded stores that had more than 36 shoppers per hour on average. Together, these findings suggest that consumers purchased more in crowded stores to "buy their way out" of close physical contact with others, with this effect being particularly pronounced under conditions of cyberspace disease salience (Otterbring, 2022; Otterbring et al., 2021).

Whereas Figure 2 may suggest relatively weak effect sizes, the average basket size was $28 \%$ larger during high $(M=$ NOK 356 , or USD 40) than during low cyberspace disease salience ( $M=$ NOK 278, or USD 31). We observed smaller differences in the average number of items sold per hour. The stores sold about $10 \%$ more items per hour during the high cyberspace disease salience period $(M=818)$ than during the low cyberspace disease salience period $(M=743)$. There were also $10 \%$ fewer shoppers per hour during high $(M=67)$ than during low $(M=75)$ cyberspace disease salience. Nevertheless, by multiplying our monetary results by the number of consumers in the stores during our studied periods, the managerial relevance of the current findings should become obvious (cf. Funder \& Ozer, 2019; Götz et al., 2022; Otterbring \& Folwarczny, 2022). Together, our results support the notion that high (vs. low) cyberspace disease salience prompts people to minimize close physical contact with strangers.

Figure 3

Interactional effect of cyberspace disease salience $\times$ the number of hourly shoppers on the two dependent measures
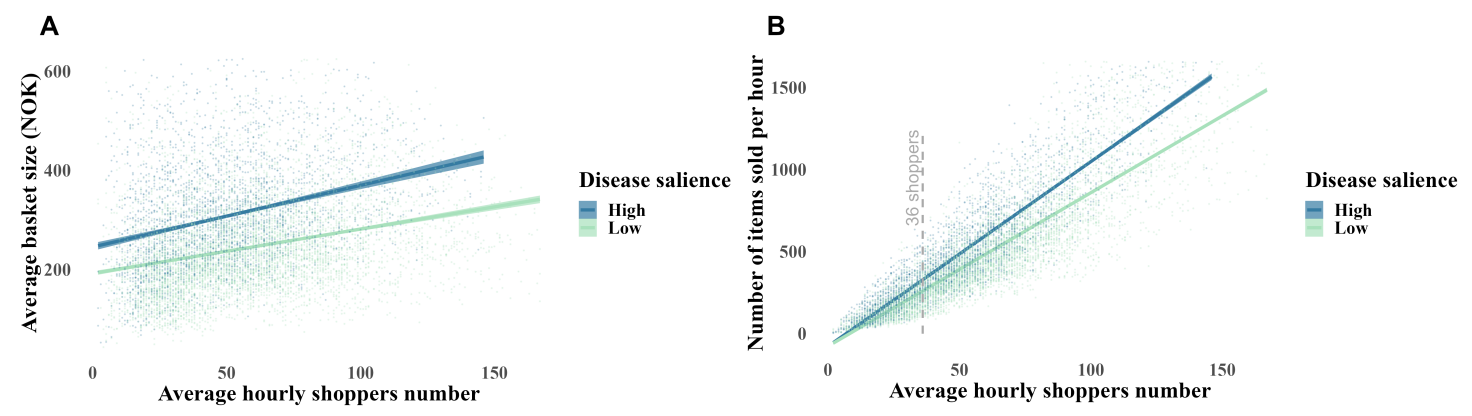

Note. The scatter plot excludes outliers, that is, data points exceeding $1.5 \times$ interquartile range above the third and below the first quartile. The shaded areas around the regression slopes depict $95 \%$ confidence intervals.

\section{Study 3}

Although Study 2 shows that people exposed to high (vs. low) cyberspace disease salience adjust their mobility behaviors at the micro-level in such a way that minimizes the frequency of interpersonal contact, it is unknown whether these effects translate to macrolevel mobility patterns. Additionally, it is unclear whether this effect occurs in all areas or only in areas with relatively high (vs. low) risk of close physical contact with strangers (vs. friends or acquaintances). Previous research has shown that people are more likely 
to engage in infection-risky behavior when in contact with romantic partners, followed by friends, acquaintances, and strangers (Tybur et al., 2020). Therefore, it is plausible that in residential areas - where people interact predominantly with non-strangers - the effects of disease salience on mobility behavior will not occur or even become reversed. Study 3 examines this possibility.

\subsection{Method}

\subsubsection{Data}

We used the Google Community Mobility Reports as our primary data source in Study 3 (for similar approaches, see e.g., Hu et al., 2021; Kim \& Kwan, 2021; Sparks et al., 2022; Zhou et al., 2021). These publicly available data, consisting of mobility patterns in most regions of the world, were collected from users who shared their location history with Google (for details, see https://www.google.com/covid19/mobility/). By default, Google grouped mobility patterns into six categories: retail and recreation, groceries and pharmacies, parks, transit stations, workplaces, and residential areas. Median daily traffic for the period January 3 to February 6, 2020, was used as the baseline. Thus, positive (negative) values, expressed as percentages, indicate a relative increase (decrease) in mobility in an area on a given day.

We divided the data into two time periods following criteria from the previous studies. The high cyberspace disease salience period for the selected European countries ranged from March 12 until May 6, 2020. From February 15 until March 11 (mobility data reported by Google for Norway begin on February 15, 2020) and from May 7 until June 20, 2020, data were coded as low cyberspace disease salience.

\subsection{Results and discussion}

We followed a similar analytic approach to Study 2, except for random effects. Because the Google Community Mobility Reports data were nested within countries and we expected the effects of cyberspace disease salience to vary across countries, we added random intercepts for countries and by-country random slopes for the effects of cyberspace disease salience on the dependent variable.

As depicted in Figure 4, during high (vs. low) pathogens salience, mobility decreased in the following five areas: retail and recreation $(b=-43.30, S E=2.10, t=-20.66, p<$ $.001)$, grocery and pharmacy $(b=-22.38, S E=1.66, t=-13.50, p<.001)$, parks $(b=$ $-34.63, S E=4.16, t=-8.33, p<.001)$, transit stations $(b=-35.29, S E=1.58, t=-22.34$, $p<.001)$, and workplaces $(b=-28.96, S E=1.31, t=-22.09, p<.001)$. In contrast, we found increased mobility in residential areas $(b=12.62, S E=0.60, t=31.09, p<.001)$.

We performed similar analyses with simple linear models separately for Norway. Replicating the pattern of findings from other countries, during high (vs. low) pathogens salience, mobility in Norway decreased in retail and recreation $(b=-32.19, S E=0.50, t=-64.10$, $p<.001)$, grocery and pharmacy $(b=-15.31, S E=0.63, t=-24.34, p<.001)$, parks $(b$ $=-12.97, S E=2.82, t=-4.60, p<.001)$, transit stations $(b=-27.91, S E=0.53, t=$ $-52.74, p<.001)$, and workplaces $(b=-27.25, S E=0.29, t=-92.91, p<.001)$. However, at the same time, mobility increased in residential areas $(b=11.48, S E=0.15, t=77.51$, 
$p<.001)$.

Consistent with our theorizing, the results of Study 3 suggest that high (vs. low) cyberspace disease salience is negatively associated with mobility in places where the risk of close physical contact with strangers is relatively high. However, high (vs. low) cyberspace disease salience is positively related to mobility in places where the risk of close physical contact with strangers is relatively low, i.e., residential areas. In other words, cyberspace disease salience appears to be negatively associated with preferences for places full of strangers, but not with places where one interacts primarily with familiar people. Remarkably, this pattern of results holds both for the European countries shown in Figure 4 , and specifically for Norway, demonstrating the generalizability of our findings.

Figure 4

Mobility patterns across the included European countries in 2020

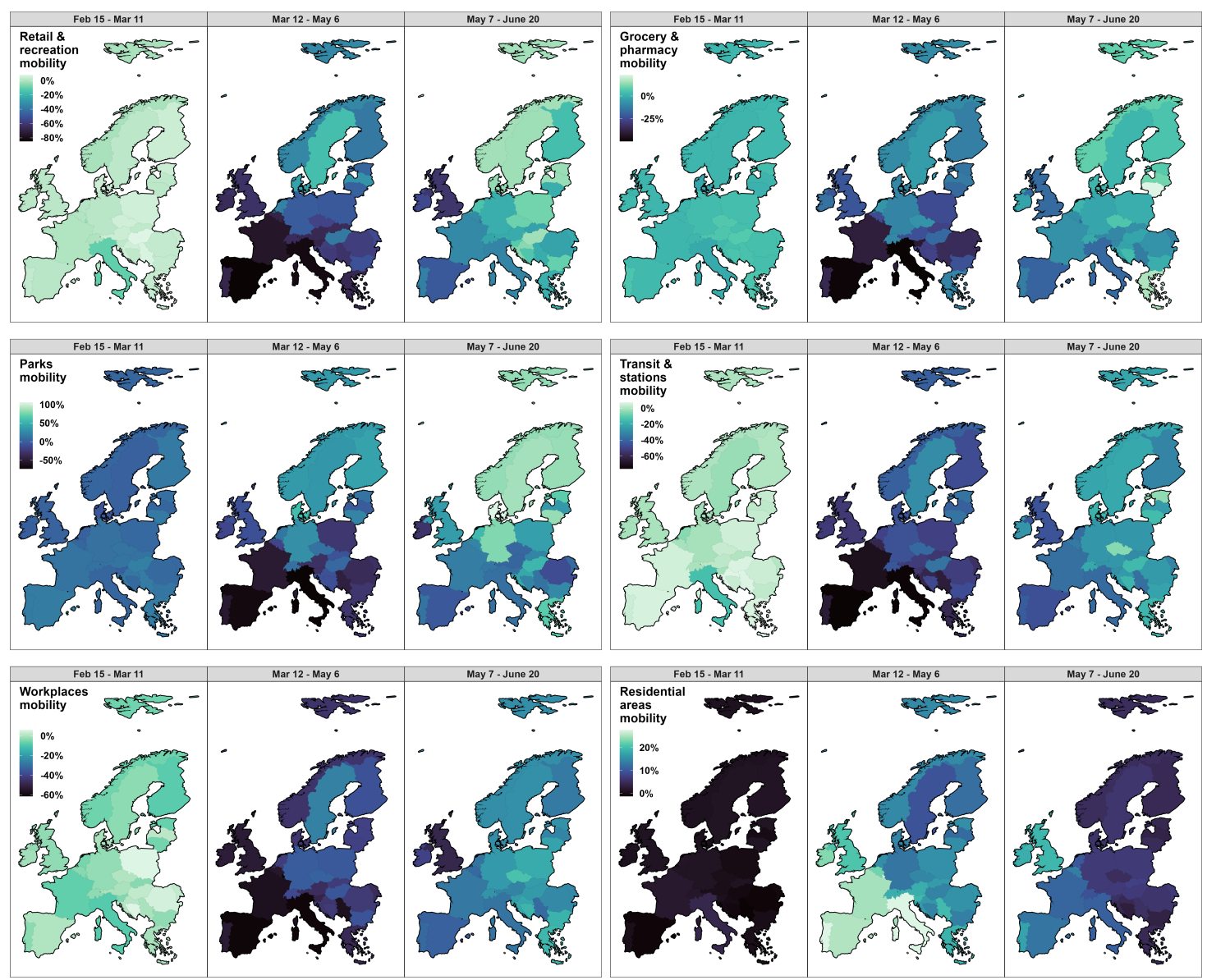

\section{Discussion}

Building on research on the behavioral immune system (Murray \& Schaller, 2016; Schaller \& Park, 2011; Tybur et al., 2020), we propose that people change their mobility behavior when cyberspace disease salience is high (vs. low) so that they minimize the likelihood of close physical contact with strangers. In Study 1, we use Google Trends data to identify the periods with the highest and lowest disease salience in cyberspace during the period studied. Analysis of hourly sales data from five grocery stores in Study 2 shows that 
mobility patterns change when cyberspace disease salience is high (vs. low): shopping trips result in the higher average basket size value, coupled with more items sold per hour. At the same time, the average number of shoppers per hour decreases. However, store crowding (i.e., the number of shoppers per hour) moderates the effect of cyberspace disease salience on the average basket size and the number of items sold per hour, so that it is stronger in the first case in crowded (vs. uncrowded) stores and occurs only in moderately to heavily crowded stores in the second case. Finally, analyzing the Google Community Mobility Reports in Study 3, we find that mobility decreases in areas where close contact with strangers is difficult to avoid under high (vs. low) cyberspace disease salience conditions. In contrast, mobility increases during this period in areas where close physical encounters with strangers are easier to avoid. Taken together, our results show broadly consistent mobility patterns under conditions of high (vs. low) cyberspace disease salience at both the micro and macro levels.

The results we obtained with respect to the average number of items sold per hour in moderately and highly crowded stores suggest that people adjust their mobility behavior at the micro-level only when physical encounters with strangers are relatively difficult to avoid. Therefore, it is plausible that people "buy their way out" of personal space violations when cyberspace disease salience is high more than when cyberspace disease salience is low, suggesting that customer personal space violations lead to paradoxical effects in which consumers spend more money despite feeling psychologically uncomfortable (Otterbring, 2022).

In summary, our findings add to the growing body of research that applies the behavioral immune system framework to understand the effects of the pandemic on human behavior (e.g., Hromatko et al., 2021). Although numerous studies show the impact of the pandemic on macro-level mobility behavior (e.g., Abu-Rayash \& Dincer, 2020; Borkowski et al., 2021; Ma, 2022; Nouvellet et al., 2021), to our knowledge, our work is the first to examine the relationship between cyberspace disease salience with micro-level mobility patterns using a unique and ecologically valid dataset from five grocery stores.

Unlike aggregate data extensively used in previous research, our hourly sales data allow us to examine by-hour mobility patterns in grocery stores. Earlier choice experiments have shown that in situations where the COVID-19 is increasingly prevalent, consumers are generally less likely to buy food in brick-and-mortar grocery stores (Grashuis et al., 2020). Similarly and in line with our findings, studies relying on self-reports show that consumers reduced the frequency of their grocery shopping during the pandemic, but also that they purchased more products than they normally would when they went grocery shopping (Schmidt et al., 2021; Wang et al., 2020). In addition, during the pandemic outbreak, self-reported data show that many consumers began shopping in the morning rather than at times when more people were in the store (Wang et al., 2020). These effects were related to negative perceptions of in-store safety measures, as well as high levels of the perceived threat from the COVID-19 and high levels of media exposure (Schmidt et al., 2021; Wang et al., 2020). Although these earlier findings from consumer self-reports are consistent with our results, our behavioral data in the form of hourly shopping metrics provide a much more nuanced and more objective representation of consumer in-store behavior during high and low disease salience. Specifically, across studies, we find that people act to minimize the risk of close physical encounters with strangers when cyberspace disease salience is high (vs. low). This finding has practical implications for retailers and 
policymakers, as more efforts should be made to encourage consumers to do more of their shopping during off-peak hours.

Prior to the pandemic, consumers in many countries increasingly preferred shorter (vs. longer) shopping trips with relatively few items purchased (Larsen et al., 2020; Sorensen et al., 2017). These short trips led many shoppers to forgo any equipment to carry the selected items to the checkout (Larsen et al., 2017). In contrast to this trend, our results show that during the period of high cyberspace disease salience associated with the pandemic outbreak, this trend reversed, at least temporarily, and shopping baskets became larger, which may indicate a greater need for shopping cart capacity. The dilemma in times of high disease salience is that shopping cart handles, as well as hand-held baskets, can be hidden reservoirs of pathogens (Gerba \& Maxwell, 2012; Irshaid et al., 2014; Mizumachi et al., 2011). Although infection risk from contact with contaminated surfaces or items is generally considered low (CDC, 2021), fear of infection and lack of knowledge may lead consumers to avoid shopping carts altogether. Studies show a positive correlation between a shopping cart and the number of items purchased (Larsen et al., 2020). Therefore, it is crucial that in-store hygiene routines are visible to consumers and that retailers participate in community education to promote hand hygiene (Larsen \& Sigurdsson, 2019). A practical idea would be to have a greeter at the entrance of a retail store to welcome each shopper and make sure to guide consumers to properly clean shopping baskets and carts so that consumers do not abandon a cart when they need it.

Given that some interventions alter mobility patterns over the long term (Skarin et al., 2017), including those developed during the pandemic (see e.g., Kang et al., 2020), retailers should consider strategies to lower the risk of infection by reducing the density of customers on the most-traveled path of their stores by separating the path of customers with relatively low demand (who come only to buy a few items) from other customers. One strategy might be to serve the low-demand customers closer to the entrance and exit, i.e., to get this segment in and out as quickly as possible without forcing them to walk through the entire store to find what they are looking for. Such a strategy requires retailers to identify the categories and items that low-demand customers are most likely to buy and then use that knowledge in managing customer flow. For example, retailers could use dedicated shelves near the entrance and checkout for products that are frequently purchased by this customer segment (see also Larsen et al., 2020; Sorensen et al., 2017). They should also make it easier for these shoppers to take shortcuts from the entrance to the checkout area (Larsen et al., 2020). This can shorten walking distances within the store and disrupt the path of many shoppers with little needs. It could also reduce the average shopping time for this customer segment, resulting in fewer customers in the store at any one time. Consequently, it would be easier for the other customers in the store to maintain social distance. Better serving customers with few needs who buy only a few items go hand in hand with infection management at the retail store level.

\section{$5 \quad$ Limitations and future research}

Some limitations of our work can serve as fruitful avenues for future research First, our dataset does not include information about which products were purchased or how consumers behaved in the store. Because our results show that, on average, consumers bought more when disease salience was high (vs. low), it is possible that they bought relatively more hedonic products such as sweets, which are often more expensive than utilitarian 
products such as fresh vegetables (Otterbring, 2019). More accurate sales data, including the use of observational technology and retail analytics (Larsen et al., 2017) or consumer receipts, are needed to test this possibility, which could have public health implications.

Second, people had more reasons to go to grocery stores to buy food (they had more needs) when cyberspace disease salience was high (vs. low). Restaurants and cafeterias were closed, leading to more food being prepared at home. At the same time, more people worked from home and therefore ate lunch at home instead of eating in the office cafeteria. Similar effects have been observed in other countries (e.g., Vazquez-Martinez et al., 2021; Young et al., 2022). More reasons to go shopping should normally lead to more trips to the grocery store. Instead, the average number of shoppers per hour decreased by ten percent. Thus, we suspect that disease salience might have had a larger negative impact on shopping trips frequency than our results suggest because more reasons to go may have attenuated the effect of disease salience on the average number of shoppers per hour. On the other hand, researchers in many countries report an increase in online grocery shopping, including home delivery, as a result of the COVID-19 (e.g., Guzman et al., 2021), which tends to reduce reasons to go to a physical grocery store. However, online grocery retailing is not yet very developed in the regions where the stores in this study are located. Therefore, we suggest further research to examine this impact on consumer travel behavior to grocery stores and in-store behavior in areas where online retailing is well developed.

Third, our data do not allow us to make clear conclusions about the causality of the relationship between cyberspace disease salience and grocery store mobility behavior. It is imperative to conduct field experiments in which cyberspace disease salience is manipulated to establish such a causal relationship. This is particularly important because it is possible that many consumers used their own bags when shopping to minimize the risk of contact with pathogens when cyberspace disease salience was high (vs. low), with the choice of carrying equipment influencing shopping behavior (Larsen et al., 2020). Thus, our results may have been influenced in part by the specific carrying equipment used by customers.

Fourth, we divided the data into periods of high and low cyberspace disease salience based in part on the presence of COVID-19-related content in cyberspace. Indeed, many studies have found an association between exposure to visual cues in cyberspace and subsequent preferences for products sold in grocery stores (e.g., Folwarczny et al., 2021; Folwarczny et al., 2022). However, we did not collect data on perceptions of the COVID-19 threat over the analyzed period. Therefore, our results do not account for variability in the perceived threat of the coronavirus, which could be the psychological mechanism driving our mobility effects. Future research should address this possibility. 


\section{References}

Abu-Rayash, A., \& Dincer, I. (2020). Analysis of mobility trends during the COVID19 coronavirus pandemic: Exploring the impacts on global aviation and travel in selected cities. Energy Research \&5 Social Science, 68, 101693. https://doi.org/10. 1016/j.erss.2020.101693

Ackerman, J. M., Hill, S. E., \& Murray, D. R. (2018). The behavioral immune system: Current concerns and future directions. Social and Personality Psychology Compass, 12(2), e12371. https://doi.org/10.1111/spc3.12371

Bates, D., Mächler, M., Bolker, B., \& Walker, S. (2015). Fitting linear mixed-effects models using lme4. Journal of Statistical Software, 67(1), 1-48. https://doi.org/10.18637/ jss.v067.i01

Borkowski, P., Jażdżewska-Gutta, M., \& Szmelter-Jarosz, A. (2021). Lockdowned: Everyday mobility changes in response to COVID-19. Journal of Transport Geography, 90, 102906. https://doi.org/10.1016/j.jtrangeo.2020.102906

CDC. (2021). Science brief: SARS-CoV-2 and surface (fomite) transmission for indoor community environments. https://www.cdc.gov/coronavirus / 2019-ncov/more/ science-and-research/surface-transmission.html

Doliński, D. (2018). Is psychology still a science of behaviour? Social Psychological Bulletin, 13(2), 1-14. https://doi.org/10.5964/spb.v13i2.25025

Folwarczny, M., Christensen, J. D., Li, N. P., Sigurdsson, V., \& Otterbring, T. (2021). Crisis communication, anticipated food scarcity, and food preferences: Preregistered evidence of the insurance hypothesis. Food Quality and Preference, 91, 104213. https://doi.org/10.1016/j.foodqual.2021.104213

Folwarczny, M., Otterbring, T., Sigurdsson, V., \& Gasiorowska, A. (2022). Seasonal cues to food scarcity and calorie cravings: Winter cues elicit preferences for energydense foods. Food Quality and Preference, 96, 104379. https://doi.org/10.1016/j. foodqual.2021.104379

Funder, D. C., \& Ozer, D. J. (2019). Evaluating effect size in psychological research: Sense and nonsense. Advances in Methods and Practices in Psychological Science, 2(2), 156-168. https://doi.org/10.1177/2515245919847202

Gerba, C. P., \& Maxwell, S. (2012). Bacterial contamination of shopping carts and approaches to control. Food Protection Trends, 32(12), 747-749.

Gómez, V. (2021). More Americans now say they prefer a community with big houses, even if local amenities are farther away. https://www. pewresearch.org/facttank/2021/08/26/more-americans-now-say-they-prefer-a-community-with-bighouses-even-if-local-amenities-are-farther-away/

Götz, F. M., Gosling, S. D., \& Rentfrow, P. J. (2022). Small effects: The indispensable foundation for a cumulative psychological science. Perspectives on Psychological Science, 17(1), 205-215. https://doi.org/10.1177/1745691620984483

Grashuis, J., Skevas, T., \& Segovia, M. S. (2020). Grocery shopping preferences during the COVID-19 pandemic. Sustainability, 12(13), 5369. https://doi.org/10.3390/ su12135369

Guzman, L. A., Arellana, J., Oviedo, D., \& Aristizábal, C. A. M. (2021). COVID-19, activity and mobility patterns in Bogotá. are we ready for a '15-minute city'? Travel Behaviour and Society, 24, 245-256.

Hromatko, I., Grus, A., \& Kolđeraj, G. (2021). Do islanders have a more reactive behavioral immune system? Social cognitions and preferred interpersonal distances 
during the COVID-19 pandemic. Frontiers in Psychology, 12, 647586. https://doi. org/10.3389/fpsyg.2021.647586

Hu, S., Xiong, C., Liu, Z., \& Zhang, L. (2021). Examining spatiotemporal changing patterns of bike-sharing usage during COVID-19 pandemic. Journal of Transport Geography, 91, 102997. https://doi.org/10.1016/j.jtrangeo.2021.102997

Hui, S. K., Bradlow, E. T., \& Fader, P. S. (2009). Testing behavioral hypotheses using an integrated model of grocery store shopping path and purchase behavior. Journal of Consumer Research, 36(3), 478-493. https://doi.org/10.1086/599046

Irshaid, F. I., Jacob, J. H., \& Khwaldh, A. S. (2014). Contamination of the handles and bases of shopping carts by pathogenic and multi-drug resistant bacteria. European Scientific Journal, 10(27), 154-169.

Kang, M., Choi, Y., Kim, J., Lee, K. O., Lee, S., Park, I. K., Park, J., \& Seo, I. (2020). COVID-19 impact on city and region: What's next after lockdown? International Journal of Urban Sciences, 24(3), 297-315. https://doi.org/10.1080/12265934. 2020.1803107

Kim, J., \& Kwan, M.-P. (2021). The impact of the COVID-19 pandemic on people's mobility: A longitudinal study of the US from March to September of 2020. Journal of Transport Geography, 93, 103039. https://doi.org/10.1016/j.jtrangeo.2021. 103039

Kuznetsova, A., Brockhoff, P. B., \& Christensen, R. H. B. (2017). ImerTest package: Tests in linear mixed effects models. Journal of Statistical Software, 82(13), 1-26. https: //doi.org/10.18637/jss.v082.i13

Larsen, N. M., \& Sigurdsson, V. (2019). What affects shopper's choices of carrying devices in grocery retailing and what difference does it make? A literature review and conceptual model. The International Review of Retail, Distribution and Consumer Research, 29(4), 376-408. https://doi.org/10.1080/09593969.2019.1581074

Larsen, N. M., Sigurdsson, V., \& Breivik, J. (2017). The use of observational technology to study in-store behavior: Consumer choice, video surveillance, and retail analytics. The Behavior Analyst, 40(2), 343-371. https://doi.org/10.1007/s40614-017-0121$\mathrm{x}$

Larsen, N. M., Sigurdsson, V., Breivik, J., \& Orquin, J. L. (2020). The heterogeneity of shoppers' supermarket behaviors based on the use of carrying equipment. Journal of Business Research, 108, 390-400. https://doi.org/10.1016/j.jbusres.2019.12.024

Larson, J. S., Bradlow, E. T., \& Fader, P. S. (2005). An exploratory look at supermarket shopping paths. International Journal of Research in Marketing, 22(4), 395-414. https://doi.org/10.1016/j.ijresmar.2005.09.005

Levin, R., Chao, D. L., Wenger, E. A., \& Proctor, J. L. (2021). Insights into population behavior during the COVID-19 pandemic from cell phone mobility data and manifold learning. Nature Computational Science, 1(9), 588-597. https://doi.org/10. 1038/s43588-021-00125-9

Long, J. A. (2019). Interactions: Comprehensive, user-friendly toolkit for probing interactions [R package version 1.1.0]. https://cran.r-project.org/package=interactions

Ma, M. Z. (2022). COVID-19 concerns in cyberspace predict human reduced dispersal in the real world: Meta-regression analysis of time series relationships across american states and 115 countries/territories. Computers in Human Behavior, 127, 107059107059. https://doi.org/10.1016/j.chb.2021.107059

Mizumachi, E., Kato, F., Hisatsune, J., Tsuruda, K., Uehara, Y., Seo, H., \& Sugai, M. (2011). Clonal distribution of enterotoxigenic staphylococcus aureus on handles 
of handheld shopping baskets in supermarkets. Journal of Applied Microbiology, 110(2), 562-567. https://doi.org/10.1111/j.1365-2672.2010.04910.x

Murray, D. R., \& Schaller, M. (2016). The behavioral immune system: Implications for social cognition, social interaction, and social influence. In Advances in Experimental Social Psychology (pp. 75-129). Elsevier. https://doi.org/10.1016/bs.aesp. 2015. 09.002

Nisbett, R. E., \& Wilson, T. D. (1977). Telling more than we can know: Verbal reports on mental processes. Psychological Review, 84(3), 231-259. https://doi.org/10.1037/ 0033-295X.84.3.231

Nouvellet, P., Bhatia, S., Cori, A., Ainslie, K. E., Baguelin, M., Bhatt, S., Boonyasiri, A., Brazeau, N. F., Cattarino, L., Cooper, L. V., et al. (2021). Reduction in mobility and COVID-19 transmission. Nature Communications, 12(1), 1-9. https://doi. org/10.1038/s41467-021-21358-2

Otterbring, T. (2019). Time orientation mediates the link between hunger and hedonic choices across domains. Food Research International, 120, 124-129. https://doi. org/10.1016/j.foodres.2019.02.032

Otterbring, T. (2021). Evolutionary psychology in marketing: Deep, debated, but fancier with fieldwork. Psychology \& Marketing, 38(2), 229-238. https://doi.org/10.1002/ mar. 21453

Otterbring, T. (2022). Physical proximity as pleasure or pain? A critical review of employeecustomer proximity in sales and services settings. Journal of Financial Services Marketing, 1-13. https://doi.org/10.1057/s41264-021-00131-y

Otterbring, T., \& Bhatnagar, R. (2022). Touch, threats, and transactions: Pandemic influences on consumer responses and the mediating role of touch likelihood when shopping for fruits and vegetables. Food Quality and Preference, 97, 104461. https: //doi.org/10.1016/j.foodqual.2021.104461

Otterbring, T., \& Folwarczny, M. (2022). Firstborns buy better for the greater good: Birth order differences in green consumption values. Personality and Individual Differences, 186, 111353. https://doi.org/10.1016/j.paid.2021.111353

Otterbring, T., Sundie, J., Li, Y. J., \& Hill, S. (2020). Evolutionary psychological consumer research: Bold, bright, but better with behavior. Journal of Business Research, 120, 473-484. https://doi.org/10.1016/j.jbusres.2020.07.010

Otterbring, T., Wu, F., \& Kristensson, P. (2021). Too close for comfort? The impact of salesperson-customer proximity on consumers' purchase behavior. Psychology $\&$ Marketing, 38(9), 1576-1590. https://doi.org/10.1002/mar.21519

Roggeveen, A. L., \& Sethuraman, R. (2020). How the COVID-19 pandemic may change the world of retailing. Journal of Retailing, 96(2), 169-171. https://doi.org/10. 1016/j.jretai.2020.04.002

Schaller, M., \& Park, J. H. (2011). The behavioral immune system (and why it matters). Current Directions in Psychological Science, 20(2), 99-103. https://doi.org/10. 1177/0963721411402596

Schmidt, S., Benke, C., \& Pané-Farré, C. A. (2021). Purchasing under threat: Changes in shopping patterns during the COVID-19 pandemic. PLOS ONE, 16(6), e0253231. https://doi.org/10.1371/journal.pone.0253231

Skarin, F., Olsson, L. E., Roos, I., \& Friman, M. (2017). The household as an instrumental and affective trigger in intervention programs for travel behavior change. Travel Behaviour \&3 Society, 6, 83-89. https://doi.org/10.1016/j.tbs.2016.08.001

Sorensen, H., Bogomolova, S., Anderson, K., Trinh, G., Sharp, A., Kennedy, R., Page, B., \& Wright, M. (2017). Fundamental patterns of in-store shopper behavior. Journal 
of Retailing and Consumer Services, 37, 182-194. https://doi.org/10.1016/j. jretconser.2017.02.003

Sorokowska, A., Saluja, S., Kafetsios, K., \& Croy, I. (2021). Interpersonal distancing preferences, touch behaviors to strangers, and country-level early dynamics of SARSCoV-2 spread. American Psychologist. https://doi.org/10.1037/amp0000919

Sorokowska, A., Sorokowski, P., Hilpert, P., Cantarero, K., Frackowiak, T., Ahmadi, K., Alghraibeh, A. M., Aryeetey, R., Bertoni, A., Bettache, K., et al. (2017). Preferred interpersonal distances: A global comparison. Journal of Cross-Cultural Psychology, 48(4), 577-592. https://doi.org/10.1177/0022022117698039

Sparks, K., Moehl, J., Weber, E., Brelsford, C., \& Rose, A. (2022). Shifting temporal dynamics of human mobility in the United States. Journal of Transport Geography, 99, 103295. https://doi.org/10.1016/j.jtrangeo.2022.103295

The Norwegian Government. (2022). Timeline: News from Norwegian Ministries about the coronavirus disease Covid-19. https://www.regjeringen.no/en/topics/koronaviruscovid-19/ timeline- for- news- from- norwegian- ministries- about- the- coronavirusdisease-covid-19/id2692402/

Tukey, J. W., et al. (1977). Exploratory data analysis. Reading.

Tybur, J. M., \& Lieberman, D. (2016). Human pathogen avoidance adaptations. Current Opinion in Psychology, 7, 6-11. https://doi.org/10.1016/j.copsyc.2015.06.005

Tybur, J. M., Lieberman, D., Fan, L., Kupfer, T. R., \& de Vries, R. E. (2020). Behavioral immune trade-offs: Interpersonal value relaxes social pathogen avoidance. Psychological Science, 31(10), 1211-1221. https://doi.org/10.1177/0956797620960011

Van Bavel, J. J., Cichocka, A., Capraro, V., Sjåstad, H., Nezlek, J. B., Pavlović, T., Alfano, M., Gelfand, M. J., Azevedo, F., Birtel, M. D., et al. (2022). National identity predicts public health support during a global pandemic. Nature Communications, 13(1), 1-14. https://doi.org/10.1038/s41467-021-27668-9

Van den Bergh, B., Dewitte, S., \& Warlop, L. (2008). Bikinis instigate generalized impatience in intertemporal choice. Journal of Consumer Research, 35(1), 85-97. https://doi.org/10.1086/525505

Van Leeuwen, F., \& Petersen, M. B. (2018). The behavioral immune system is designed to avoid infected individuals, not outgroups. Evolution and Human Behavior, 39(2), 226-234. https://doi.org/10.1016/j.evolhumbehav.2017.12.003

Vazquez-Martinez, U. J., Morales-Mediano, J., \& Leal-Rodriguez, A. L. (2021). The impact of the COVID-19 crisis on consumer purchasing motivation and behavior. European Research on Management and Business Economics, 27(3), 100166. https://doi. org/10.1016/j.iedeen.2021.100166

Wang, Y., Xu, R., Schwartz, M., Ghosh, D., \& Chen, X. (2020). COVID-19 and retail grocery management: Insights from a broad-based consumer survey. IEEE Engineering Management Review, 48(3), 202-211. https://doi.org/10.1109/EMR.2020.3011054

Welsch, R., Wessels, M., Bernhard, C., Thönes, S., \& von Castell, C. (2021). Physical distancing and the perception of interpersonal distance in the COVID-19 crisis. Scientific Reports, 11(1), 1-9. https://doi.org/10.1038/s41598-021-90714-5

Young, M., Soza-Parra, J., \& Circella, G. (2022). The increase in online shopping during COVID-19: Who is responsible, will it last, and what does it mean for cities? Regional Science Policy \& Practice, 1-17. https://doi.org/doi.org/10.1111/rsp3. 12514

Zhou, Y., Liu, X. C., \& Grubesic, T. (2021). Unravel the impact of COVID-19 on the spatio-temporal mobility patterns of microtransit. Journal of Transport Geography, 97, 103226. https://doi.org/10.1016/j.jtrangeo.2021.103226 


\section{Appendix}

Table S1

Study 2 descriptive statistics per each shopping hour

\begin{tabular}{|c|c|c|c|c|c|c|c|}
\hline Time (h) & Disease salience & $M$ basket size (NOK) & $S D$ basket size & $M$ items sold & $S D$ items sold & $M$ shoppers & $S D$ shoppers \\
\hline 7 & high & 245.68 & 199.79 & 126.58 & 78.98 & 19.84 & 9.74 \\
\hline 7 & low & 161.71 & 157.92 & 111.53 & 85.18 & 26.82 & 25.37 \\
\hline 8 & high & 345.97 & 185.58 & 270.64 & 229.73 & 25.76 & 12.68 \\
\hline 8 & low & 220.81 & 145.35 & 223.54 & 217.21 & 35.71 & 29.72 \\
\hline 9 & high & 375.74 & 174.97 & 488.23 & 504.91 & 38.21 & 22.41 \\
\hline 9 & low & 256.26 & 129.56 & 367.05 & 392.57 & 41.93 & 30.91 \\
\hline 10 & high & 365.47 & 156.24 & 788.60 & 768.27 & 65.08 & 35.75 \\
\hline 10 & low & 271.72 & 121.67 & 632.60 & 603.63 & 69.03 & 41.72 \\
\hline 11 & high & 360.42 & 145.05 & 1056.72 & 983.15 & 88.47 & 50.54 \\
\hline 11 & low & 278.37 & 119.90 & 887.56 & 796.05 & 94.63 & 52.37 \\
\hline 12 & high & 376.89 & 138.92 & 1178.57 & 1219.39 & 93.61 & 63.04 \\
\hline 12 & low & 300.58 & 116.21 & 1018.59 & 991.08 & 97.38 & 61.84 \\
\hline 13 & high & 375.21 & 136.20 & 1200.38 & 1261.80 & 96.20 & 65.57 \\
\hline 13 & low & 298.05 & 118.32 & 1117.57 & 1071.27 & 109.09 & 66.53 \\
\hline 14 & high & 379.88 & 135.30 & 1266.58 & 1271.86 & 100.67 & 65.13 \\
\hline 14 & low & 298.73 & 118.31 & 1203.13 & 1154.57 & 116.38 & 70.90 \\
\hline 15 & high & 378.83 & 143.42 & 1355.56 & 1319.81 & 108.65 & 62.42 \\
\hline 15 & low & 315.97 & 121.43 & 1343.50 & 1178.49 & 125.61 & 67.40 \\
\hline 16 & high & 392.59 & 150.33 & 1263.87 & 1367.47 & 96.29 & 60.32 \\
\hline 16 & low & 328.19 & 120.53 & 1209.44 & 1096.18 & 109.95 & 64.56 \\
\hline 17 & high & 382.00 & 144.22 & 1038.88 & 1184.44 & 81.09 & 55.91 \\
\hline 17 & low & 320.60 & 124.79 & 972.57 & 974.48 & 89.23 & 59.49 \\
\hline 18 & high & 369.32 & 142.69 & 931.83 & 1002.87 & 74.26 & 50.20 \\
\hline 18 & low & 307.75 & 125.91 & 878.46 & 844.30 & 81.86 & 51.11 \\
\hline 19 & high & 357.63 & 147.27 & 757.93 & 799.73 & 64.36 & 39.15 \\
\hline 19 & low & 288.33 & 119.74 & 696.56 & 642.19 & 71.36 & 42.41 \\
\hline 20 & high & 338.07 & 154.49 & 552.26 & 606.34 & 46.43 & 28.07 \\
\hline 20 & low & 276.26 & 121.04 & 516.99 & 441.32 & 55.09 & 33.77 \\
\hline 21 & high & 332.50 & 174.99 & 389.62 & 410.50 & 34.26 & 18.38 \\
\hline 21 & low & 262.83 & 123.74 & 334.55 & 251.75 & 39.31 & 31.23 \\
\hline 22 & high & 298.35 & 151.94 & 254.49 & 237.55 & 26.12 & 14.02 \\
\hline 22 & low & 233.45 & 107.17 & 219.96 & 140.96 & 30.04 & 13.40 \\
\hline
\end{tabular}


Table S2

The interactional effect of cyberspace disease salience and store crowding on the average basket size

\begin{tabular}{lc}
\hline & Average basket size \\
\hline Intercept & -.15 \\
Cyberspace disease salience (high) & {$[-.81, .50]$} \\
& $.57^{* * *}$ \\
Shoppers number & {$[.47, .67]$} \\
& $.12^{* * *}$ \\
Cyberspace disease salience $($ high $) \times$ Shoppers number & {$[.10, .13]$} \\
& $.11^{* * *}$ \\
Note: & {$[.09, .14]$} \\
& ${ }^{*} \mathrm{p}<.05 ;{ }^{* *} \mathrm{p}<.01 ;{ }^{* * *} \mathrm{p}<.001$ \\
& Brackets show $95 \% \mathrm{CIs}$
\end{tabular}

Table S3

The interactional effect of cyberspace disease salience and store crowding on the number of items sold per hour

Items sold per hour

\begin{tabular}{lc} 
Intercept & -.05 \\
Cyberspace disease salience (high) & {$[-.29, .19]$} \\
& $.21^{* * *}$ \\
Shoppers number & {$[.15, .26]$} \\
& $.70^{* * *}$ \\
Cyberspace disease salience (high) $\times$ Shoppers number & {$[.69, .71]$} \\
& $.24^{* * *}$ \\
Note: & {$[.22, .25]$} \\
\hline & ${ }^{*} \mathrm{p}<.05 ;{ }^{* *} \mathrm{p}<.01 ;{ }^{* * *} \mathrm{p}<.001$ \\
& Brackets show $95 \%$ CIs
\end{tabular}

